\title{
Ultrasonic and thermal properties of borate and phosphate glasses containing bismuth and lead
}

\begin{abstract}
Systematic series of (B2O3,P2O5)-Bi2O3-PbO glasses have been successfully prepared by using the rapid quenching technique in which each oxide content changes for every series on the basis of its weight percentage. Their amorphous natures were confirmed earlier by the $\mathrm{x}$ ray diffraction technique. The experimental results show that the density of both glasses, determined by using the Archimedes principle, increases with the glass modifier content. This is due to the replacement of $\mathrm{Bi} 2 \mathrm{O} 3$ and $\mathrm{PbO}$ in the borate and phosphate glassy networks. The molar volume for borate glass increases with the addition of bismuth and lead oxides, but a reverse trend occurs for the phosphate glass. The longitudinal and shear ultrasound velocities, determined by the MBS 8000 system, of both lead bismuth borate and phosphate glasses show a decreasing trend as more $\mathrm{PbO}$ and $\mathrm{Bi} 2 \mathrm{O} 3$ are added to the glass system. The increase in $\mathrm{PbO} / \mathrm{Bi} 2 \mathrm{O} 3$ content was probably related to the progressive increase in the concentration of non-bridging oxygen (NBOs). Thermal studies of the glass, using the Labsys DTA-Setaram machine, show that the value of the glass transition temperature $(\mathrm{Tg})$ is closely related to the chemical bond in the system. In lead bismuth borate glasses, the addition of more $\mathrm{Pb} 2+$ and $\mathrm{Bi} 3+$ results in a more dominant ionic bond character in the system and hence decreases $\mathrm{Tg}$ of the sample. However, in lead bismuth phosphate glasses, the addition of $\mathrm{Pb} 2+$ and $\mathrm{Bi} 3+$ not only failed to weaken the covalent character in Pï Oï P bonds, but strengthened it further, leading to an increment in the values of $\mathrm{Tg}$.
\end{abstract}

Keyword: Bismuth; Lead; Thermal properties; Ultrasonic 